\title{
Investigation of hydrate slurry flow behaviors in deep-sea pipes with different inclination angles
}

\author{
Shupeng Yao, Yuxing Li*, Wuchang Wang, Guangchun Song, Zhengzhuo Shi, Xiaoyu Wang, and Shuai Liu \\ Shandong Key Laboratory of Oil-Gas Storage and Transportation Safety, China University of Petroleum, Qingdao 266580, \\ Shandong, PR China
}

Received: 29 December 2018 / Accepted: 21 March 2019

\begin{abstract}
The marine area is the main direction of the development of oil and gas resources in the world. The pipeline transportation technology of natural gas hydrate slurry plays an important role in the exploitation of marine oil and gas and the exploitation of marine gas hydrate resources. In order to study the influence of pipe inclination on pipeline transportation, population balance model based on hydrate particle aggregation dynamics was coupled with the Eulerian-Eulerian two-fluid multiphase flow model to simulate the flow behaviors of hydrate slurry flow in pipes with different inclination angles. In the study, three variables of inclination, flow rate and initial particle size were considered. The results show that tilted pipes are beneficial to hydrate slurry transport rather than harmful. Meanwhile, higher flow rates and lower initial particle sizes are beneficial for promoting the flow safety of hydrate slurry transport. However, the flow pressure drop of the hydrate slurry increases with the increase of the flow rate and the decrease of the initial particle size, which is not conducive to the economics of mining. The research results in this paper can provide reference for the research of hydrate slurry flow safety and parameter guidance for hydrate solid fluidized mining.
\end{abstract}

\section{Introduction}

Natural Gas Hydrates (NGH), also known as "combustible ice", are clathrate inclusion compounds. They are snowy solid formed by some components in natural gas and water under high pressure and low temperature conditions [1-3]. In the study of hydrate slurry flow, scholars tend to study the traditional thermodynamic methods to change the hydrate formation conditions (such as changing the hydrate formation temperature, pressure, etc.) in the early days. Preventing the formation of hydrates in oil and gas pipeline transportation by this method, and increasing the safety, economy and reliability of natural gas pipeline transportation [4-6]. In the 1980s, Vysniauskas and Bishnoi began to research on hydrate kinetics, which opened a new chapter in the safety of hydrate flow from "preventing" to "controlling" [7]. Nowadays, hydrate slurry flow research has a rich content, and many scholars from various countries have carried out many loop experiments and numerical simulation studies [8-10].

Marine oil and gas resources are the main replacement for the world's oil and gas resources. Marine areas, especially deep-sea areas, are rich in oil and gas resources, and attract the attention of researchers and institutions around the world. In recent years, the exploration and development

\footnotetext{
* Corresponding author: Iyx13370809333@163.com
}

of deep-sea natural gas hydrate resources have been highly concerned by more and more countries [11-13]. It is estimated that the reserves of natural gas hydrates in the world are twice that of the known carbon-containing compounds, and about $95 \%$ of them are found in the deep-sea area [14]. Therefore, the successful mining of hydrates in the deep sea can effectively alleviate the world's energy problems. Meanwhile, the study of the flow behaviors of natural gas hydrate slurry is of great significance for the development of deep-sea oil and gas and the exploitation of natural gas hydrate.

Among the hydrate resources in the deep sea, most of the hydrates are stored in the superficial layer of the seabed, with a shallow depth, no dense cover, weak joints, fragile and non-diagenetic properties, known as non-diagenetic hydrates [15]. Due to these properties of non-diagenetic hydrates, the mining risk is high and it is difficult to mine through traditional mining methods. To exploit nondiagenetic hydrates effectively, Zhou et al. proposed the solid fluidized mining method for the first time. Solid fluidized mining utilizes the stability of hydrates on the seabed to break up hydrates into particles. Then, after mixing and fluidizing with seawater, NGH becomes a controllable oil and gas resource through the gas-liquid-solid multiphase lifting system. This hydrate mining method can effectively avoid geological disasters and greenhouse effects that caused by massive decomposition of hydrates $[15,16]$. 
Hydrate slurry pipeline transportation is the core of solid fluidized mining, and it is also the core link of "cold flow" transportation in oil and gas pipeline transportation. However, experiments for hydrate slurry flow often require a large cost, so it is difficult to generalize. In recent years, with the development of Computational Fluid Dynamics (CFD), numerical simulation has become an effective way to conduct hydrate slurry flow research. Balakin et al. studied the flow deposition of R11 hydrate in turbulent flow system by CFD simulation [17, 18]. Fatnes simulated the hydrate flow behaviors in horizontal tubes by ANSYS CFX [19]. Song et al. simulated the agglomeration, breakage and deposition of $\mathrm{CCl}_{3} \mathrm{~F}$ (R11) hydrate and applied the population balance model in his study [20-23]. However, the current simulations of hydrate slurry by CFD are mainly concentrated in horizontal pipes, and there is less simulation in vertical pipes related to hydrate mining. Zhou et al. studied the hydrate decomposition critical point, liquid holdup and solid phase content in vertical wellbore by finite difference iterative numerical simulation method [16]. Liu et al. studied the behaviors of solid-liquid two-phase flow and gas-liquid-solid three-phase flow in vertical pipe transportation of natural gas hydrate slurry using the Euler multiphase flow model and FiniteRate/Eddy-Dissipation model in the CFD models [24]. However, in the above studies, the influence of the inclination of the hydrate pipe was not considered. During the hydrate slurry transport in the deep-sea, the inclination of the pipeline due to the influence of the seabed undulation and the pipe lifting also has a great influence on the flow behaviors of the hydrate slurry. Therefore, the influence of pipe inclination on the flow behaviors of hydrate slurry is worthy of further study.

In this paper, based on the traditional Eulerian-Eulerian two-fluid model, the population balance model based on hydrate particle aggregation dynamics was added to simulate the flow in hydrate slurry. Therefore, the calculation of the agglomeration and breakage of natural gas hydrate particles is more accurate, which means a more accurate reflection of the flow of hydrates in the pipeline. Moreover, it is considered that the hydrate is under stable conditions in the simulations, that is, hydrate formation and decomposition do not occur in the simulation. The flow behaviors of hydrate slurry in different inclination pipes in hydrate slurry transportation have been mainly studied. Besides, the effect of the initial particle size and flow rate is mainly considered. The research results in this study can provide theoretical support for the study of flow behaviors of non-diagenetic hydrate mining and hydrate slurry technology.

\section{Numerical models}

\subsection{Geometric model}

The geometric model of this simulation work is based on the loop established by Balakin et al. in the experimental study of the flow behaviors of R11 hydrate slurry in the loop [25]. This is because the data of the loop experiment is relatively complete, which is convenient for further verification of the accuracy of the model. The geometric model is a threedimensional pipeline model with a length of $2.0 \mathrm{~m}$ and a diameter of $4.52 \mathrm{~cm}$. The model is shown in Figure 1, and $Z$ is the vertical direction.

When building the mesh of the model, consider the effect of boundary layer, six layers of mesh are settled in the near wall area. For other meshes, hexahedrons and a step length of $1 \mathrm{~mm}$ are used. This geometric model consists of 170180 hexahedral meshes with a mesh quality of 0.917 . And the mesh dependency of the geometric model is good for numerical simulation.

\subsection{Basic assumptions}

There are four basic assumptions in this paper: 1) The hydrate slurry is isothermal in the process of flowing. 2) Interface mass transfer is not considered, that is, neglecting the formation and dissociation of the hydrate. 3) The hydrate slurry used in the simulation only consists of water phase and hydrate phase and cannot be compressed. 4) The process of hydrate-wall adhesion is neglected.

\subsection{Multiphase model and viscous model}

In this paper, multiphase model select Eulerian-Eulerian two-fluid model, which consists of continuity equations (Eq. (1)), momentum equations (Eq. (2)) and several constitutive equations used for the closure of the equation set:

$$
\begin{gathered}
\frac{\partial\left(\rho_{\mathrm{i}} \alpha_{\mathrm{i}}\right)}{\partial t}+\nabla \cdot\left(\rho_{\mathrm{i}} \alpha_{\mathrm{i}} \boldsymbol{u}_{\mathrm{i}}\right)=0 \\
\frac{\partial\left(\rho_{\mathrm{i}} \alpha_{\mathrm{i}} \boldsymbol{u}_{\mathrm{i}}\right)}{\partial t}+\nabla \cdot\left(\rho_{\mathrm{i}} \alpha_{\mathrm{i}} \boldsymbol{u}_{\mathrm{i}} \boldsymbol{u}_{\mathrm{i}}\right)=-\alpha \nabla p+\alpha_{\mathrm{i}} \rho_{\mathrm{i}} \boldsymbol{g}+\nabla \cdot \tau_{\mathrm{i}}+\boldsymbol{M}_{\mathrm{i}},
\end{gathered}
$$

where, i represents for water phase or hydrate phase, $\rho$ is density, $\alpha$ is volume fraction, $\nabla$ is gradient operator, $\boldsymbol{u}$ is velocity vector, $p$ is pressure, $\boldsymbol{\tau}$ is stress tensor and $\boldsymbol{M}$ is the interphase momentum exchange.

In this study, mainly considering solid-liquid two-phase coupling when establishing the multiphase model. During the FLUENT simulation, liquid-solid coupling is achieved by the interphase momentum exchange. What's more, when calculating the interphase momentum exchange $\boldsymbol{M}$, the main consideration is interphase drag force, which is mainly composed of shape resistance and frictional resistance. The interphase force model can be calculated using the Gidaspow model [26]. As follows:

In this paper, when $\alpha_{\mathrm{s}} \leq 20 \%$, the equation of Wen-Yu (Eq. (3)) is selected to calculate $\beta$, which can be written as:

$$
\beta=\frac{3}{4} C_{\mathrm{D}} \frac{\left(1-\alpha_{\mathrm{s}}\right) \alpha_{\mathrm{s}} \rho_{\mathrm{l}}\left|\vec{v}_{\mathrm{l}}-\vec{v}_{\mathrm{s}}\right|}{d_{p}}\left(1-\alpha_{\mathrm{s}}\right)^{-2.65} .
$$

When $\alpha_{\mathrm{s}}>20 \%$, the equation of Ergun (Eq. (4)) is selected to calculate $\beta$, which can be written as:

$$
\beta=150 \frac{\alpha_{\mathrm{s}}^{2} \mu_{1}}{\left(1-\alpha_{\mathrm{s}}\right) d_{p}^{2}}+\frac{7}{4} \frac{\alpha_{\mathrm{s}} \rho_{\mathrm{l}}\left|\vec{v}_{\mathrm{l}}-\vec{v}_{\mathrm{s}}\right|}{d_{p}} .
$$




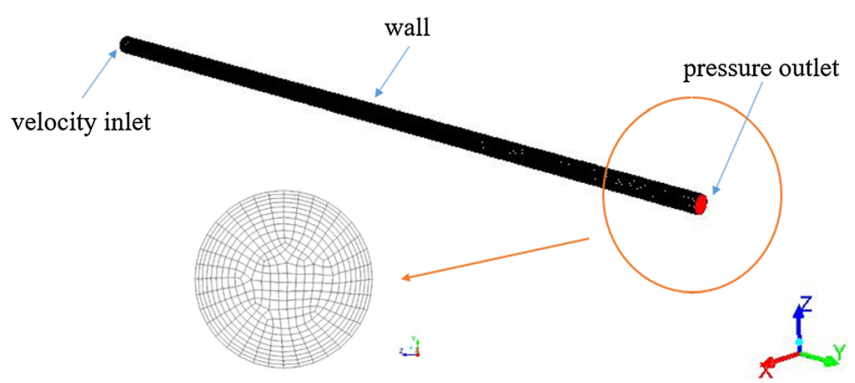

Fig. 1. Mesh of the geometric model.

Then, an interphase force model (Eq. (5)) is established, as can be seen below:

$$
\vec{F}_{\mathrm{D}}=\beta \cdot \vec{v}_{r}
$$

where, $\beta$ is the momentum transfer coefficient, 1 and s represent for water and hydrate, $C_{\mathrm{D}}$ is the drag coefficient, $\vec{F}_{\text {D }}$ is interphase drag force. $v_{r}$ is interphase relative velocity.

In this paper, it is also necessary to calculate the viscosity of the hydrate phase, which can be calculated by the following equation (Eq. (6)):

$$
\mu_{\mathrm{s}}=\frac{\mu_{\mathrm{m}}-\mu_{1} \alpha_{1}}{\alpha_{\mathrm{s}}},
$$

where, the surface viscosities $\mu_{\mathrm{m}}$ of R11 hydrate slurry and natural gas hydrate slurry are calculated from RoscoeBrinkman equation [27] (Eq. (7)) and Thomas equation [28] (Eq. (8)):

$$
\begin{gathered}
\mu_{\mathrm{m}}=\mu_{1}\left(1-\alpha_{\mathrm{s}}\right)^{-2.5} \\
\mu_{\mathrm{m}}=\frac{\mu_{1}\left(1+2.5 \alpha_{\mathrm{s}}+10.05 \alpha_{\mathrm{s}}^{2}+0.00273 \mathrm{e}^{16.6 \alpha_{\mathrm{s}}}\right)-\mu_{1} \alpha_{1}}{\alpha_{\mathrm{s}}} .
\end{gathered}
$$

In this paper, standard $k-\varepsilon$ model is selected for the viscous model. More detailed information of this part can be found elsewhere [17] and no repetition will be listed here.

\subsection{Population Balance Model (PBM)}

In this paper, PBM can be expressed as follows [29] (Eq. (9)):

$$
\begin{aligned}
\frac{\mathrm{d} n(L, t)}{\mathrm{d} t}= & \frac{1}{2} \int_{0}^{L} a \beta\left(L-L^{\prime}, L^{\prime}\right) n\left(L-L^{\prime}, t\right) n\left(L^{\prime}, t\right) \mathrm{d} L^{\prime} \\
& -n(L, t) \int_{0}^{\infty} a \beta\left(L, L^{\prime}\right) n\left(L^{\prime}, t\right) \mathrm{d} L^{\prime} \\
& +\int_{L}^{\infty} b\left(L L^{\prime}\right) S\left(L^{\prime}\right) n\left(L^{\prime}, t\right) \mathrm{d} L^{\prime} \\
& -S(L) n(L, t),
\end{aligned}
$$

where, $n(L, t)$ is the quantity density of the discrete, $\beta\left(L-L^{\prime}, L^{\prime}\right)$ is the collision frequency, $a$ is the agglomeration efficiency after collision, and $a \beta\left(L-L^{\prime}, L^{\prime}\right)$ is the agglomeration kernel of the collision. $S\left(L^{\prime}\right)$ is the breakage frequency, $b\left(L \mid L^{\prime}\right)$ is the size distribution of the discrete phase resulting from breakage, and $b\left(L \mid L^{\prime}\right) S\left(L^{\prime}\right)$ is the breakage kernel of the discrete phase. Based on hydrate particle aggregation dynamics, the calculating methods of the parts in equation (9) are given below.

In terms of collision frequency, the collision caused by differential settlement and flow shear is mainly considered, and the sum the two parts is taken as the actual collision frequency of the hydrate particles. Differential sedimentation $\beta_{\mathrm{DS}}$ is calculated by the formula (Eq. (10)) proposed by Camp [30]:

$$
\beta_{\mathrm{DS}}=\frac{\pi}{4}\left(L_{\mathrm{i}}+L_{\mathrm{j}}\right)^{2}\left|V_{\mathrm{i}}-V_{\mathrm{j}}\right|,
$$

where, the settling velocity $V$ can be obtained by equation (11):

$$
V=347.5602 L^{1.54} .
$$

When hydrate particles are larger than the Kolmogorov scale, flow shear $\beta_{\mathrm{ST}}$ is calculated by the formula (Eq. (12)) established by Abrahamson [31], as shown below:

$$
\beta_{\mathrm{ST}}=2^{3 / 2} \sqrt{\pi} \frac{\left(L_{\mathrm{i}}+L_{\mathrm{j}}\right)^{3}}{4} \sqrt{\left(u_{\mathrm{i}}^{2}+u_{\mathrm{j}}^{2}\right)^{2}} .
$$

When hydrate particles are smaller than the Kolmogorov scale, the formula (Eq. (13)) established by Saffman and Turner [32] is selected, as shown below:

$$
\beta_{\mathrm{ST}}=\sqrt{\frac{8 \pi}{15}} G \frac{\left(L_{\mathrm{i}}+L_{\mathrm{j}}\right)^{3}}{8},
$$

where, $G$ is a local parameter referred to as the absolute velocity gradient, and it is defined as follows (Eq. (14)):

$$
G=\sqrt{\frac{\varepsilon}{v}} .
$$

In this paper, curvilinear model proposed by Van de Ven and Mason (Eq. (15)) is selected, which is shown as below [33]:

$$
a=k\left(\frac{H}{36 \pi \mu_{l} G R^{3}}\right)^{0.18},
$$

where, $k$ is a parameter related to fluid properties, $H$ is the Hamaker constant, $R$ is the harmonic radius of the tow colliding particles.

In terms of breakage kernel, Lehr model is selected. It contains breakage frequency and size distribution of the discrete phase. More detailed information of this part can be found elsewhere [34] and no repetition will be listed here.

\subsection{Model solution}

In this paper, the CFD software FLUENT 15.0 is used to solve the models. For boundary conditions, the inlet is set as velocity inlet and the outlet is set as pressure outlet. What's more, second order upwind difference scheme is selected in momentum equation discretization and phase coupled SIMPLE scheme is used in pressure-velocity 
coupling. Besides, PBM is solved by the discrete method in this paper. When the maximum residual value is no more than $10^{-5}$, the model solution process ends. The key parameters involved in the solution process (concentration, density, etc.) and their corresponding values are listed in Table 1, and the simulation conditions are listed in Table 2 $[35,36]$.

\subsection{Model validation}

The model was validated using experimental data from Balakin et al. $[17,18]$ to ensure the accuracy of the model. And the experimental data of pressure drop are selected to verify the simulation results. Table 3 is the simulation conditions of model verification, and Table 4 is the comparison of pressure drop between experimental results and simulation results. It can be seen from the verification results that the flow model in this paper can accurately simulate the hydrate flow behaviors.

\section{Numerical simulation}

In this paper, it is considered that the hydrate slurry is stably present in two phases of hydrate particles and water, and there is no formation or dissociation of hydrate. Therefore, the hydrate particles mainly have two behaviors of agglomeration and breakage. According to the behaviors of hydrates, the population balance model based on aggregation dynamics of hydrate particle is added. When the hydrate slurry is transported in the marine area, the existence of undulations in the seabed and the rise of the pipeline from the seabed to the sea surface have a great influence on the flow behaviors of the hydrate slurry, making the hydrate multiphase flow more complicated. The flow behaviors of the hydrate slurry in each inclination pipe are studied below, and the influence of the inclination on the flow behaviors of the particle size distribution, concentration distribution and pressure drop of the hydrate slurry are analyzed.

\subsection{Effect of inclination on particle size distribution of hydrate slurry}

The distribution of the hydrate particle size in the pipe is an important part of the study of the behaviors of the hydrate slurry, which has an important influence on the properties of the viscosity of the hydrate slurry. In this paper, we study the flow behaviors of hydrate slurry without reaching decomposition conditions. Although the formation and dissociation of hydrates are not considered, the hydrate particles will aggregate and break in the pipe, which leads to a change in the particle size during the flow. The particle size distribution of the hydrate slurry will be analyzed based on the results of the simulation.

It can be seen from Figures 2-5 that under the simulated conditions, when the hydrate slurry flows in the pipe, the particle size distribution of the hydrate under different inclination angles is relatively homogeneous and symmetrical. Moreover, the particle size in the middle
Table 1. Parameters and their values used in model.

\begin{tabular}{lc}
\hline Parameters & Values \\
\hline Water phase density & $1000 \mathrm{~kg} / \mathrm{m}^{3}$ \\
R11 hydrate density & $1138 \mathrm{~kg} / \mathrm{m}^{3}$ \\
Gas hydrate density & $956.1 \mathrm{~kg} / \mathrm{m} \cdot \mathrm{s}$ \\
Continuous phase viscosity & $1.79 \mathrm{cP}$ \\
Maximum packing fraction & 0.55 \\
Restitution coefficient & 0.9 \\
$H$ & $4 \times 10^{-20} \mathrm{~J}$ \\
$m$ & 1.90 \\
$E$ & $800 \mathrm{~s}^{0.90} / \mathrm{m}$ \\
Volume fraction & $30 \%$ \\
Surface tension & 0.07 \\
$k$ & 0.87 \\
Continuous phase viscosity & $1.79 \mathrm{cP}$ \\
\hline
\end{tabular}

region is lower and more uniform, and the particle size and particle size variation gradient in the near wall region are larger. This can be explained by the aggregation kinetics of hydrate particles in the pipeline. In the simulated conditions, the flow rate of the hydrate slurry is relatively high, so the hydrate particles are relatively less affected by gravity, and the collision aggregation is mainly affected by the flow shear. In the near wall region, the hydrate slurry has the strongest flow shearing. Therefore, the probability that the hydrate particles collide and aggregate to form large particle size hydrate particles is also the largest, and the hydrate particle size increases as well. On the contrary, in the middle region of the pipe, the flow shearing effect of the hydrate slurry is relatively weak, the probability of collision and aggregation of the hydrate particles is small, and the particle size of the hydrate is also small.

Analysis of Figures 2-4 separately. It can be found that under the simulated conditions, when the initial particle size and flow rate of the hydrate particles are constant, the particle size distribution of the hydrate slurry is more homogeneous and symmetrical with the increase of the inclination of the pipe, but the change is small, and the particle size does not change significantly. This indicates that when the flow rate is large, the hydrate slurry flows more stably in the pipe and is less affected by gravity. Comparing Figures 2-4, we can see that when the inclination of the hydrate slurry pipe and the initial particle size of the hydrate particles are constant, the particle size distribution of the hydrate slurry is more homogeneous and symmetrical as the flow rate increases. But the maximum value of the hydrate particle size decreases as the flow rate increases. This is because the larger the flow rate, the stronger the flow shearing of the hydrate slurry, and the smaller the influence by gravity, so the particle size distribution is more symmetrical and homogeneous. However, the stronger the flow shear of the hydrate slurry, the smaller the maximum particle size that can be maintained when the hydrate remains in balance between agglomeration and breakage. 
Table 2. Simulation condition list.

\begin{tabular}{|c|c|c|c|c|c|c|c|c|c|c|c|}
\hline Cases & Inclination $/^{\circ}$ & $\begin{array}{c}\text { Initial } \\
\text { particle } \\
\text { size } / \mu \mathrm{m}\end{array}$ & $\begin{array}{l}\text { Flow } \\
\text { rate/ } \\
\mathrm{m} \cdot \mathrm{s}^{-1} \\
\end{array}$ & Cases & Inclination $/{ }^{\circ}$ & $\begin{array}{c}\text { Initial } \\
\text { particle } \\
\text { size } / \mu \mathrm{m}\end{array}$ & $\begin{array}{l}\text { Flow } \\
\text { rate/ } \\
\mathrm{m} \cdot \mathrm{s}^{-1} \\
\end{array}$ & Cases & Inclination $/{ }^{\circ}$ & $\begin{array}{c}\text { Initial } \\
\text { particle } \\
\text { size } / \mu \mathrm{m}\end{array}$ & $\begin{array}{l}\text { Flow } \\
\text { rate } / \\
\mathrm{m} \cdot \mathrm{s}^{-1} \\
\end{array}$ \\
\hline 1 & 0 & 10 & 0.5 & 16 & 5 & 100 & 0.5 & 31 & 60 & 50 & 0.5 \\
\hline 2 & 0 & 10 & 1 & 17 & 5 & 100 & 1 & 32 & 60 & 50 & 1 \\
\hline 3 & 0 & 10 & 1.5 & 18 & 5 & 100 & 1.5 & 33 & 60 & 50 & 1.5 \\
\hline 4 & 0 & 50 & 0.5 & 19 & 30 & 10 & 0.5 & 34 & 60 & 100 & 0.5 \\
\hline 5 & 0 & 50 & 1 & 20 & 30 & 10 & 1 & 35 & 60 & 100 & 1 \\
\hline 6 & 0 & 50 & 1.5 & 21 & 30 & 10 & 1.5 & 36 & 60 & 100 & 1.5 \\
\hline 7 & 0 & 100 & 0.5 & 22 & 30 & 50 & 0.5 & 37 & 90 & 10 & 0.5 \\
\hline 8 & 0 & 100 & 1 & 23 & 30 & 50 & 1 & 38 & 90 & 10 & 1 \\
\hline 9 & 0 & 100 & 1.5 & 24 & 30 & 50 & 1.5 & 39 & 90 & 10 & 1.5 \\
\hline 10 & 5 & 10 & 0.5 & 25 & 30 & 100 & 0.5 & 40 & 90 & 50 & 0.5 \\
\hline 11 & 5 & 10 & 1 & 26 & 30 & 100 & 1 & 41 & 90 & 50 & 1 \\
\hline 12 & 5 & 10 & 1.5 & 27 & 30 & 100 & 1.5 & 42 & 90 & 50 & 1.5 \\
\hline 13 & 5 & 50 & 0.5 & 28 & 60 & 10 & 0.5 & 43 & 90 & 100 & 0.5 \\
\hline 14 & 5 & 50 & 1 & 29 & 60 & 10 & 1 & 44 & 90 & 100 & 1 \\
\hline 15 & 5 & 50 & 1.5 & 30 & 60 & 10 & 1.5 & 45 & 90 & 100 & 1.5 \\
\hline
\end{tabular}

Table 3. Simulation condition list for model verification.

\begin{tabular}{lccc}
\hline $\begin{array}{l}\text { Flow } \\
\text { rate/ } \\
(\mathrm{m} / \mathrm{s})\end{array}$ & $\begin{array}{c}\text { Volume } \\
\text { fraction/ } \\
\%\end{array}$ & $\begin{array}{c}\text { Continuous } \\
\text { phase } \\
\text { viscosity } / \mathrm{cP}\end{array}$ & $\begin{array}{c}\text { Initial } \\
\text { particle } \\
\text { size/ } \mu \mathrm{m}\end{array}$ \\
\hline 1.5 & 14.1 & 1.79 & 100 \\
1.5 & 22.5 & 1.79 & 100 \\
1.5 & 30.4 & 1.79 & 100 \\
\hline
\end{tabular}

Figure 5 is a graph showing the particle size distribution of hydrate particles in the outlet under various conditions. Comparing the figures (a), (d), (g) (Figs. (b), (e), (h) or (c), (f), (i)), it can be found that when the inclination and flow rate are constant, as the particle size increases, the maximum particle size of the hydrate particles in the pipe also increases. This is because the aggregation and breakage of the hydrate particles are based on the initial particle diameter, so that when the initial particle diameter is large, there is a greater probability of forming particles having a larger particle diameter. In addition, it can be found that as the initial particle size increases, the coincidence degree of the hydrate particle size distribution under each inclination condition becomes worse and worse. This indicates that as the hydrate particle size increases, the mass of the hydrate particles also increases, and the influence from gravity also increases. What's more, this phenomenon becomes more and more obvious as the flow rate decreases. Meanwhile, it can be found that the particle size is slightly higher in the lower part of the pipe than in the upper part of the pipe when the flow rate is lower.
Table 4. Comparison of experimental results and simulation results.

\begin{tabular}{lcc}
\hline $\begin{array}{l}\text { Simulation } \\
\text { results/ } \\
\mathrm{Pa} \cdot \mathrm{m}^{-1}\end{array}$ & $\begin{array}{c}\text { Experimental } \\
\text { results } / \\
\mathrm{Pa} \cdot \mathrm{m}^{-1}\end{array}$ & $\begin{array}{c}\text { Relative } \\
\text { error } / \%\end{array}$ \\
\hline 553 & 624.5 & 12.9 \\
629 & 664.3 & 5.6 \\
669 & 723.3 & 8.1 \\
\hline
\end{tabular}

This is because, although the total flow rate of the hydrate slurry is evenly distributed across the pipe section, as shown in Figure 6, the flow rate of the pipe in the Z-axis direction will appear higher at the bottom, which leads to an increase in the flow shear of the hydrate slurry at the bottom of the pipe.

From the above analysis, in the hydrate slurry transportation, the higher flow rate and lower initial particle size are favorable for the homogeneous distribution of the particle size of the hydrate slurry, and it is not easy to aggregate to form larger particles.

\subsection{Effect of inclination on concentration distribution of hydrate slurry}

The concentration distribution of the hydrate slurry in the pipe is also one of the important flow behaviors. It has important significance for the study of hydrate aggregation, sedimentation and other behaviors. Based on the simulation results, the concentration distribution of hydrate slurry under different inclination angles will be analyzed. 

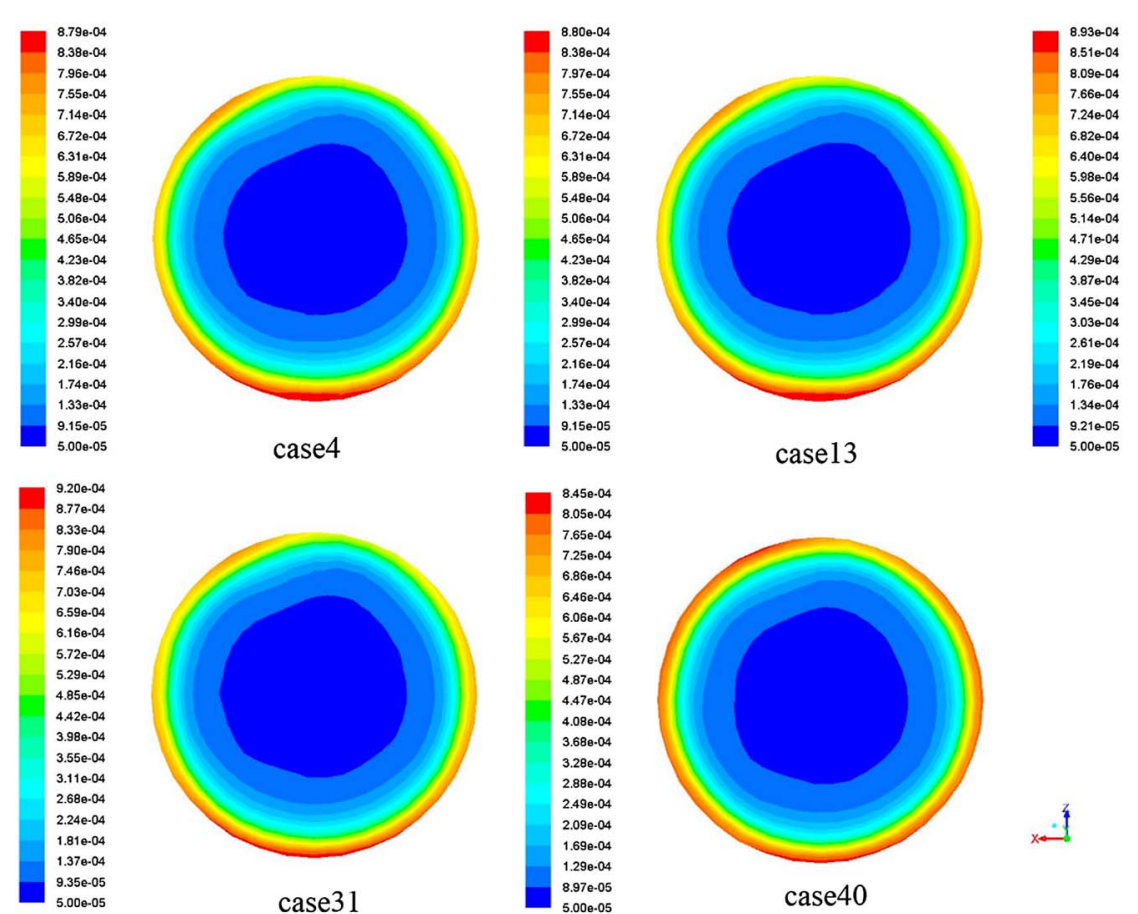

case13

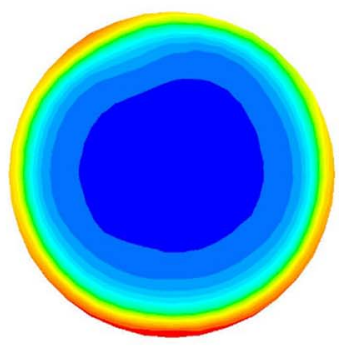

case22
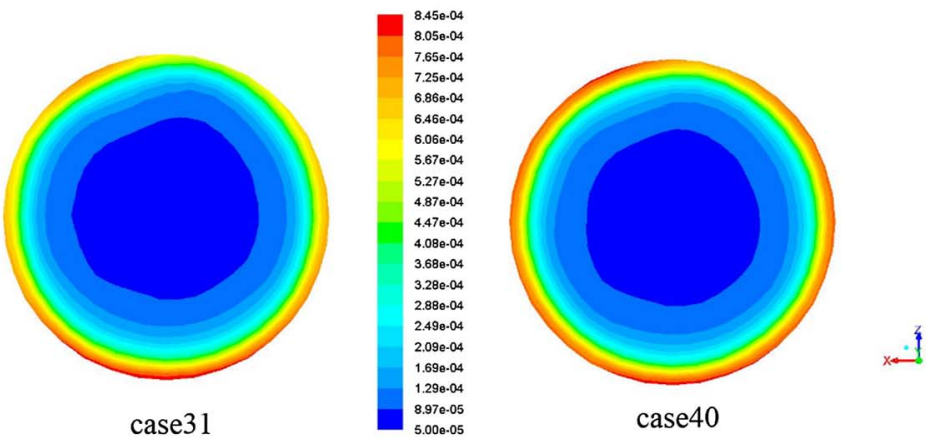

Fig. 2. When the initial particle size of hydrate is $50 \mu \mathrm{m}$ and the average flow velocity is $0.5 \mathrm{~m} / \mathrm{s}$, the particle size distribution in the outlet section of different inclination angles (inclination angle increases in turn).
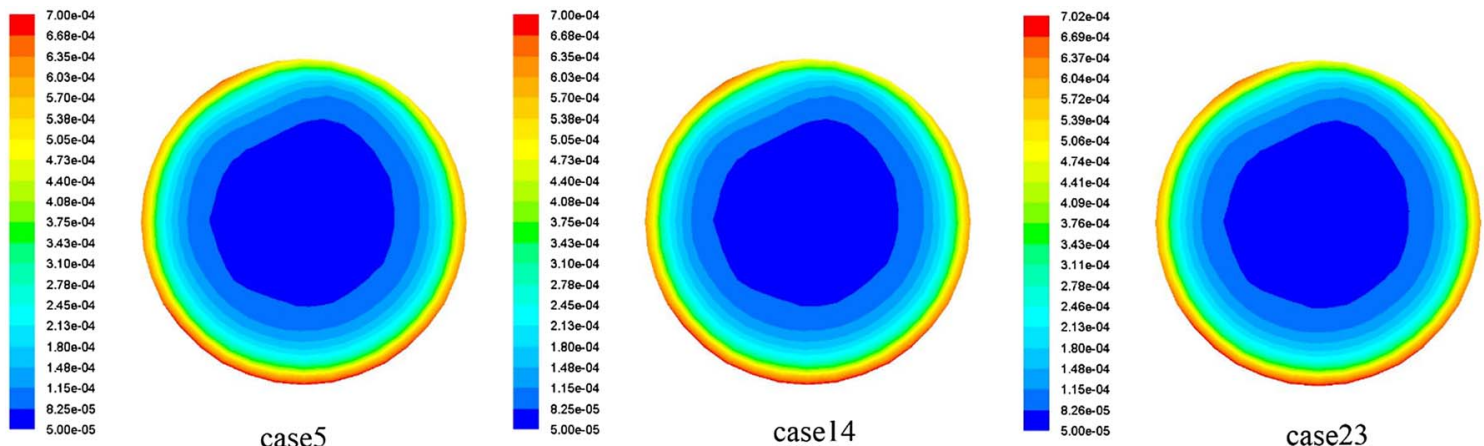

case 14

case 23
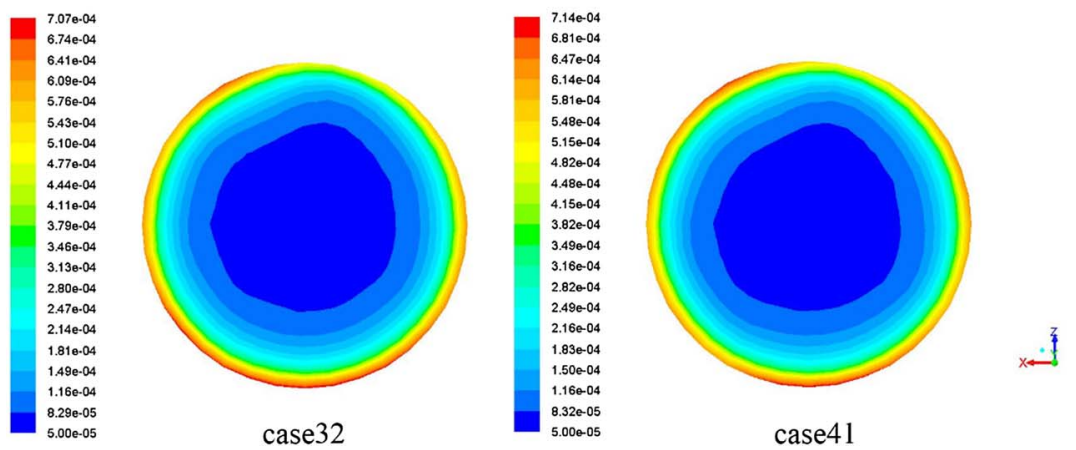

Fig. 3. When the initial particle size of hydrate is $50 \mu \mathrm{m}$ and the average flow velocity is $1.0 \mathrm{~m} / \mathrm{s}$, the particle size distribution in the outlet section of different inclination angles (inclination angle increases in turn)

It can be seen from Figures 7-10 that, similar to the particle size distribution, under the simulated conditions, when the hydrate slurry flows in the pipe, the hydrate concentration distribution under the different inclination angles is relatively homogeneous and symmetrical. It is also shown that the middle region has a lower concentration and 

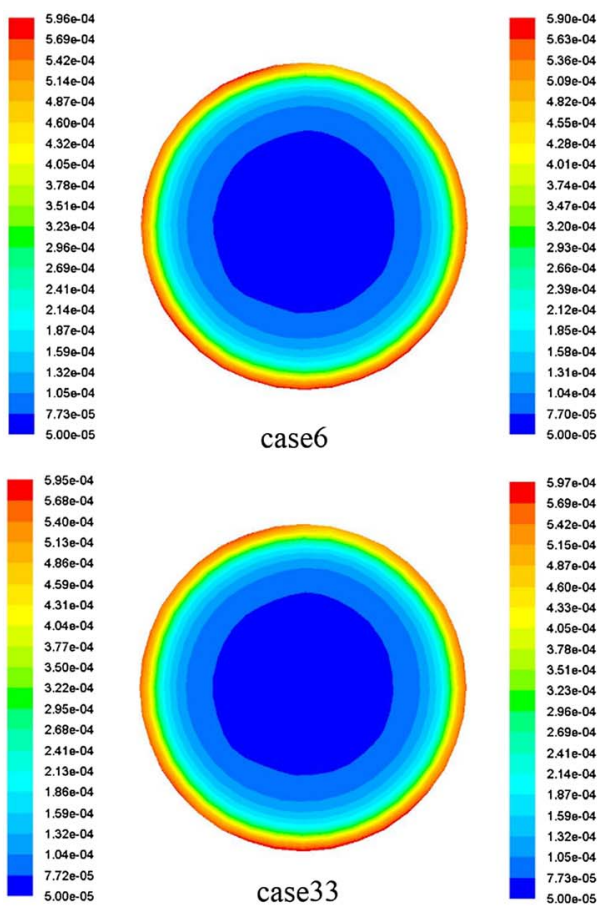

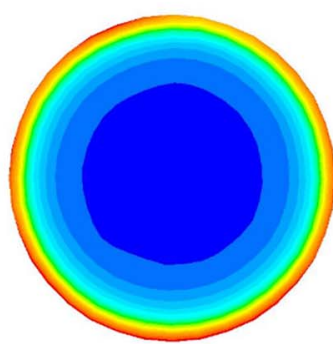

case 15
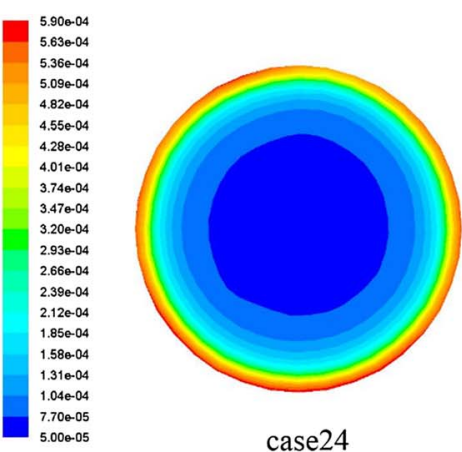

case 24
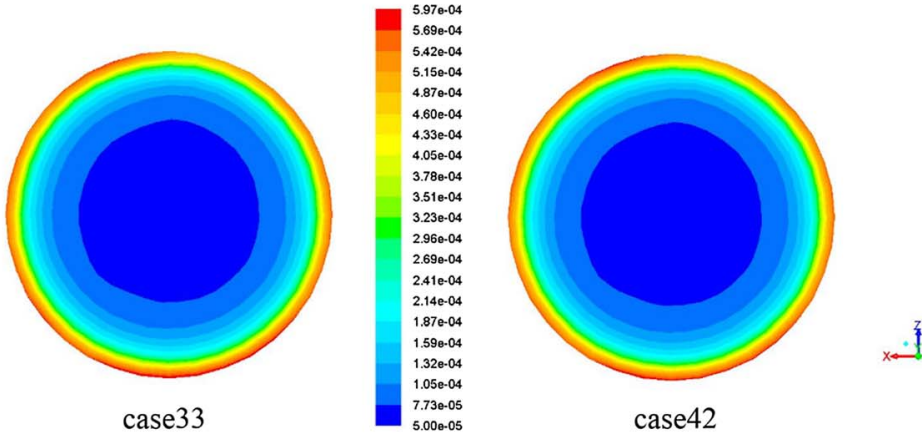

Fig. 4. When the initial particle size of hydrate is $50 \mu \mathrm{m}$ and the average flow velocity is $1.5 \mathrm{~m} / \mathrm{s}$, the particle size distribution in the outlet section of different inclination angles (inclination angle increases in turn).

(a)

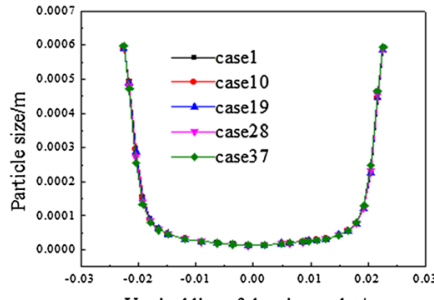

(d)

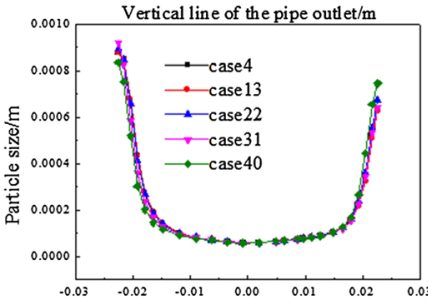

(g)

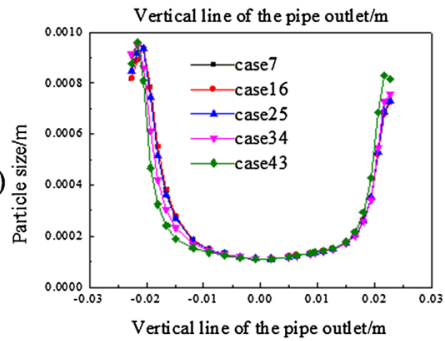

(b)

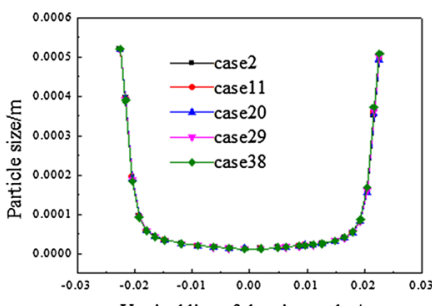

(e)

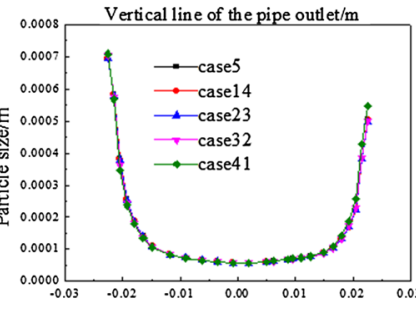

(h)

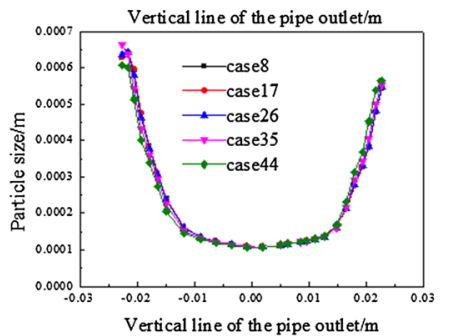

(c)

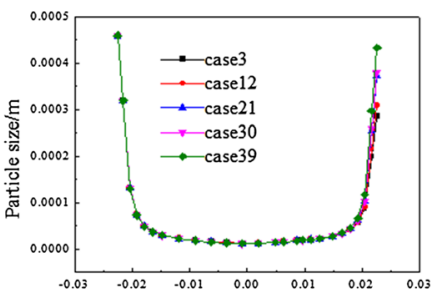

(f)

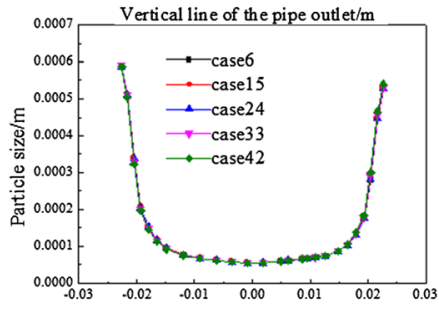

(i)

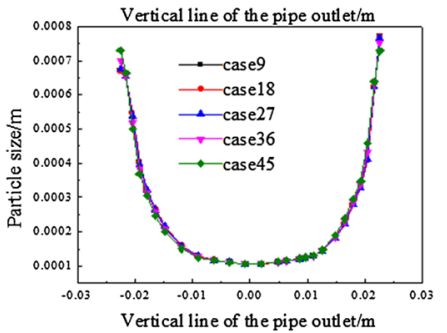

Fig. 5. XY plot of particle size distribution in the outlet radial cross section (cases 1-45).

is more homogeneous, while the near wall region has a larger concentration. This is because in this simulation condition, the flow rate of the simulated conditions is relatively large, and the liquid carrying effect is strong, so that the hydrate does not settle down deposition, and the concentration is uniformly distributed over the entire section. 

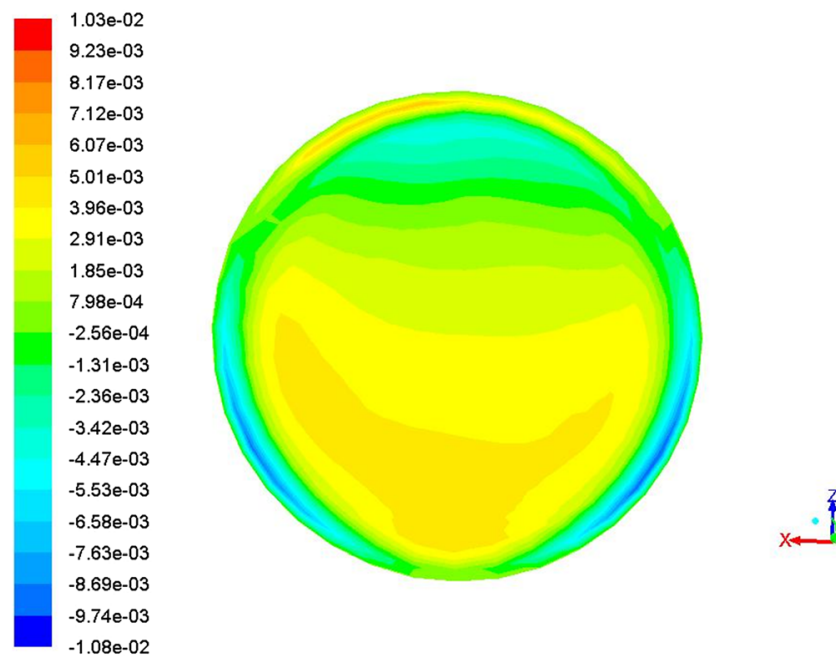

Fig. 6. When inclination is $0^{\circ}$, the initial particle size of hydrate is $100 \mu \mathrm{m}$ and the average flow velocity is $1.5 \mathrm{~m} / \mathrm{s}$, the $Z$-axis flow rate distribution in the outlet section of different inclination angles.

Moreover, since the flow rate is high in the middle region of the pipe and is low in near the wall region, the concentration is low in the middle region and is high in the near wall region. Higher flow rate increases the dispersion coefficient of the hydrate particles, resulting in a lower concentration and a more homogeneous distribution, while the surrounding area is unevenly distributed due to a decrease in flow rate, and hydrate particles are accumulated.

As shown in the analysis of Figures 7-9, when the initial particle size and flow rate of the hydrate particles are constant, the concentration distribution of the hydrate is more homogeneous in the outlet cross section as the inclination of the pipe increases, and this phenomenon becomes more prominent as the flow rate of the hydrate slurry decreases. This is because when the pipe inclination is small, the flow direction of the hydrate slurry is perpendicular to the direction of gravity, and the hydrate is moved to the upper part of the pipe by buoyancy due to the small density, so that the upper part of the hydrate concentration is higher than the lower part. What's more, as the inclination of the pipe increases, the flow direction of the hydrate slurry will gradually coincide with the direction of gravity, and the influence of gravity will gradually decrease. However, when the flow rate is large, the hydrate particles are much more affected by the flow shear than the gravity, so that the concentration of the hydrate slurry can be uniformly and symmetrically distributed in the horizontal pipe.

According to Figure 10, comparing (a), (d), (g) [(b), (e), (h) or (c), (f), (i)], it can be seen that as the initial particle size of the hydrate increases, the hydrate particles are more affected by gravity, and the tendency of the hydrate to move to the upper part of the pipe increases, and the heterogeneous distribution of the hydrate slurry concentration in the pipe section is enhanced. Therefore, the distribution of the hydrate slurry concentration on the cross section of the pipe is more heterogeneous. Meanwhile, the highest concentration of hydrate at the near wall region is also greater, and the highest concentration region gradually moves toward the center of the pipe. This can be explained by the preferential concentration of hydrate particles. When the hydrate particles are small, the particles follow the water movement and diffusion, tending to gather in the high vortex region. The large particles have a larger inertia, which are less affected by the vortex, and are gradually thrown out as the particle size increases [37].

As mentioned above, a larger flow rate enables the hydrate slurry concentration to be more homogeneous in the pipe. Besides, the high concentration zone is closer to the central region of the pipe, and it is not prone to the accumulation of hydrates due to gravity. This reduces the risk of shrinking the cross-sectional area of the pipe and even blocking the pipe. As the particle size increases, the heterogeneous distribution of hydrate slurry concentration increases. Although the high concentration zone of the hydrate slurry will move closer to the center of the pipe, the maximum concentration will increase, increasing the risk of blocking. Therefore, from the aspect of concentration, large flow rate and small initial particle size are favorable for the safe transportation of the hydrate slurry.

\subsection{Effect of inclination on flow pressure drop of hydrate slurry}

The flow pressure drop of hydrate slurry is the main factor determining the production power demand. Therefore, the study of the flow pressure drop behaviors of hydrate slurry in different inclination angles pipes is of great significance to engineering production. Based on the results of this simulation, the law of the pressure drop behaviors of hydrate slurry flow under different working conditions will be analyzed.

According to Figure 11, when the initial particle size and flow rate of the hydrate slurry are constant, the pressure gradient of the hydrate slurry gradually decreases as the inclination of the pipe increases, and the decreasing tendency gradually decreases. This is because the flow pressure drop is caused by the collision of the particles with the wall. Under the influence of gravity, the smaller the angle of inclination, the stronger the collision between hydrate particles and the wall. Comparing the curves of cases 1-3 (cases 4-6 or cases 7-9), it can be seen that as the flow rate of the hydrate slurry increases, the pressure gradient of the hydrate slurry in the pipe increases greatly, and the increasing tendency gradually increases. This is because the flow pressure drop of the hydrate slurry is mainly caused by the frictional resistance. Specifically, it can be analyzed by the Darcy-Weisbach equation that the flow pressure drop along the pipe is proportional to the square of the flow velocity, so the increase of the flow rate has a great influence on the flow pressure drop of the hydrate slurry in the pipe. Comparing the curves of cases $1,4,7$ (cases 2, 5,8 or cases $3,6,9$ ), as the initial particle size of the hydrate particles increases, the unit flow pressure drop of the hydrate slurry gradually decreases, and the larger the flow rate, the more obvious the phenomenon. This is because when the concentration is the same, the particle size 

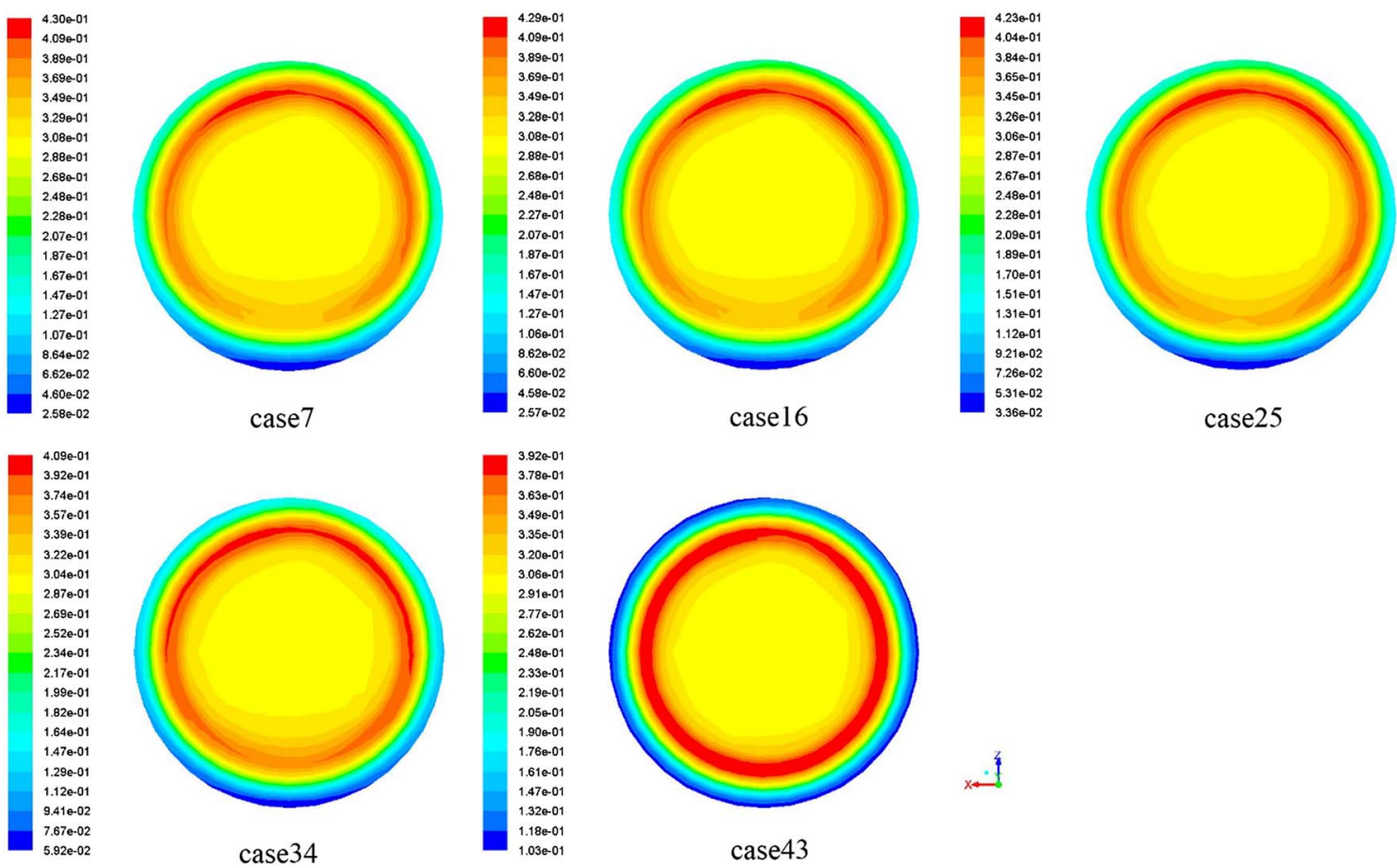

Fig. 7. When the initial particle size of hydrate is $100 \mu \mathrm{m}$ and the average flow velocity is $0.5 \mathrm{~m} / \mathrm{s}$, the concentration distribution in the outlet section of different inclination angles (inclination angle increases in turn).
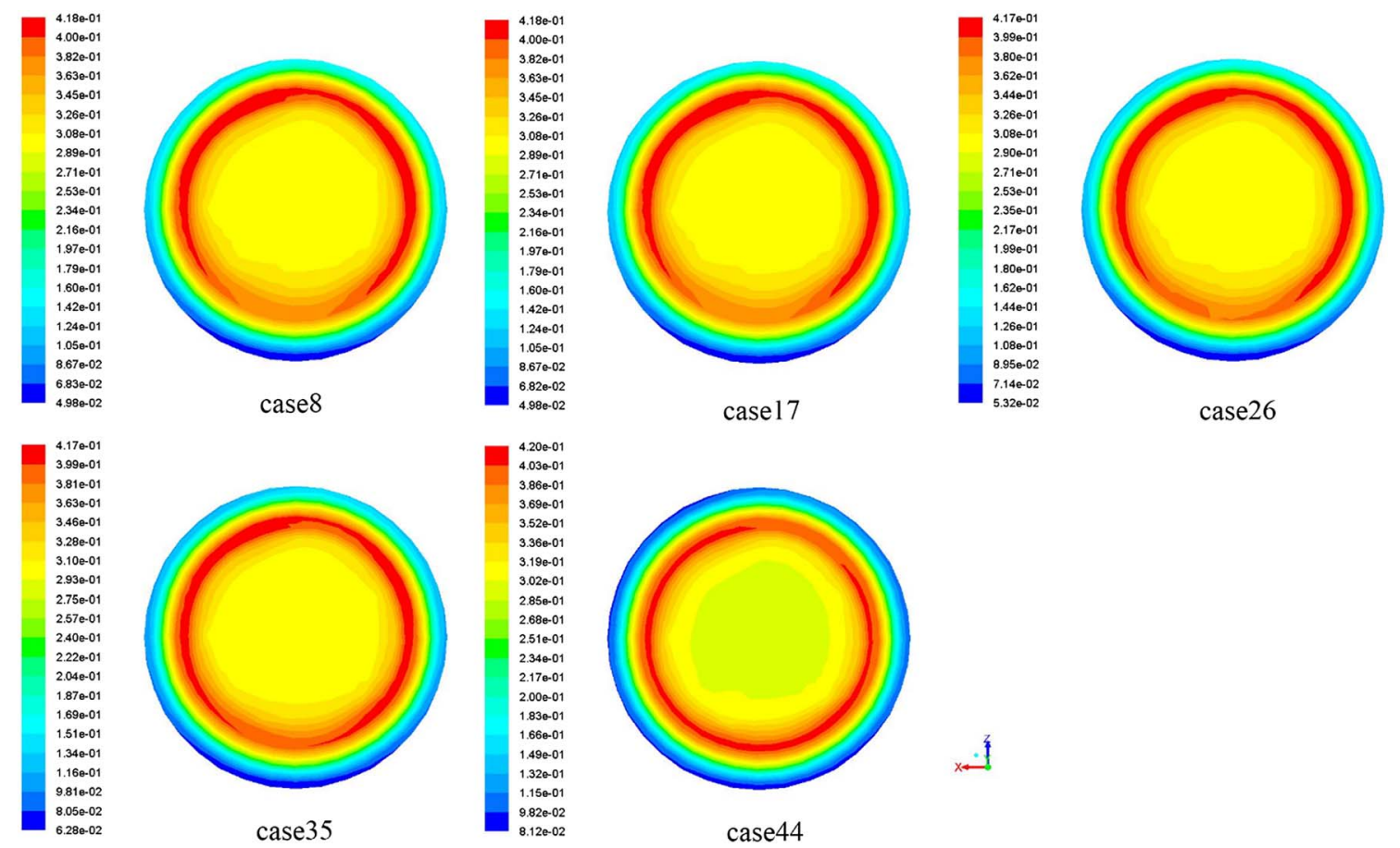

Fig. 8. When the initial particle size of hydrate is $100 \mu \mathrm{m}$ and the average flow velocity is $1.0 \mathrm{~m} / \mathrm{s}$, the concentration distribution in the outlet section of different inclination angles (inclination angle increases in turn). 

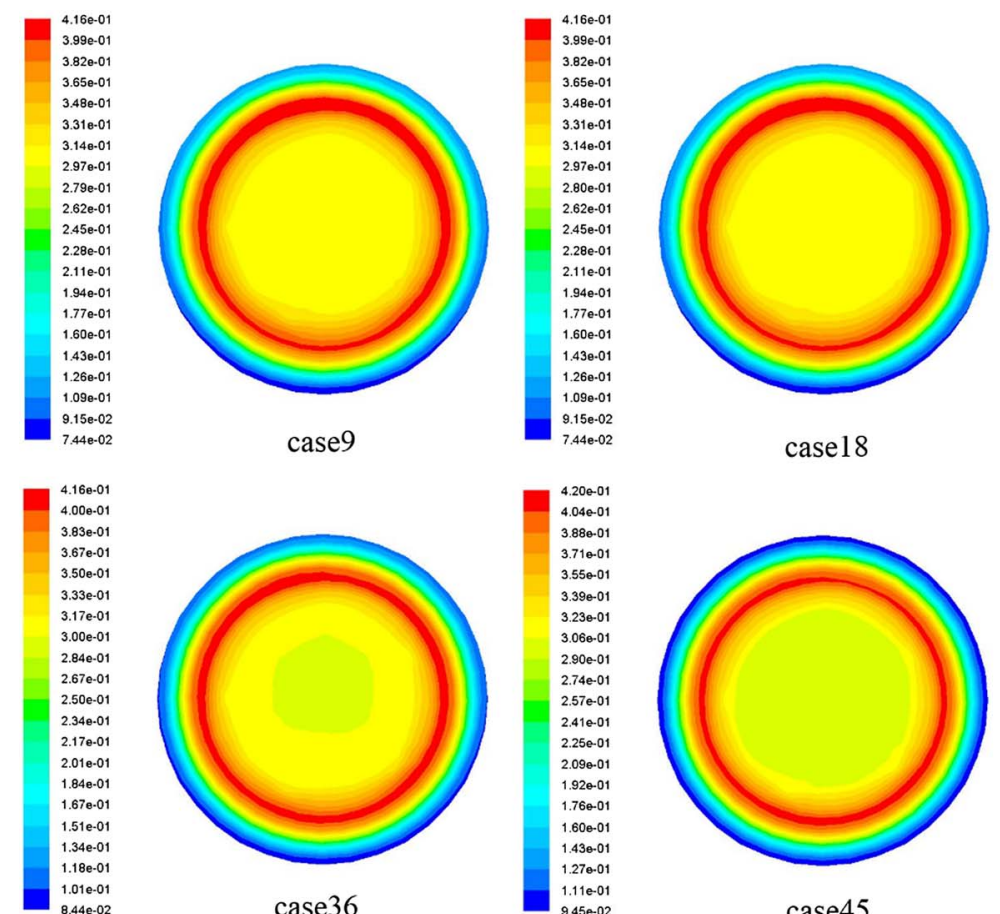

case 9

$440 \cdot 02$

case 18
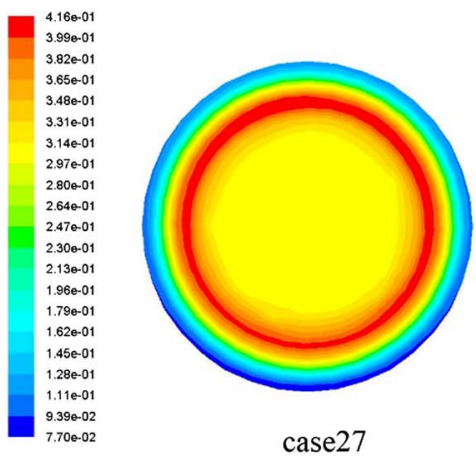

case 27
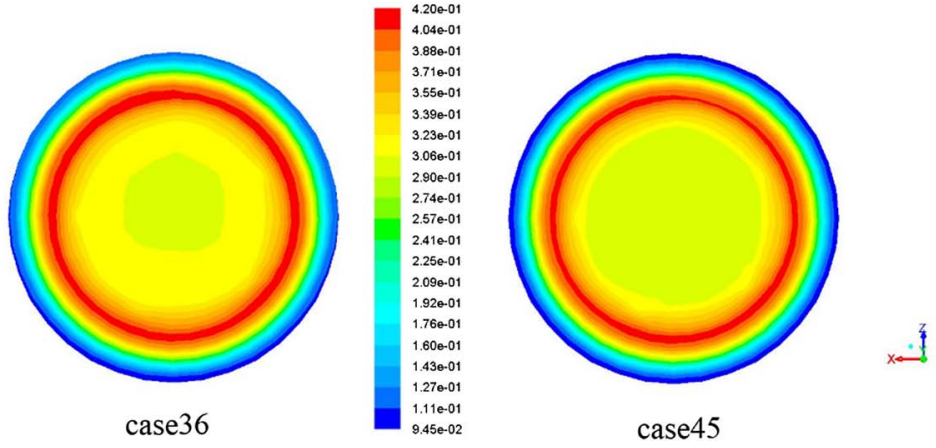

Fig. 9. When the initial particle size of hydrate is $100 \mu \mathrm{m}$ and the average flow velocity is $1.5 \mathrm{~m} / \mathrm{s}$, the concentration distribution in the outlet section of different inclination angles (inclination angle increases in turn).

(a)

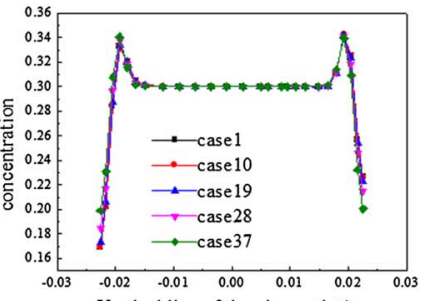

(d)
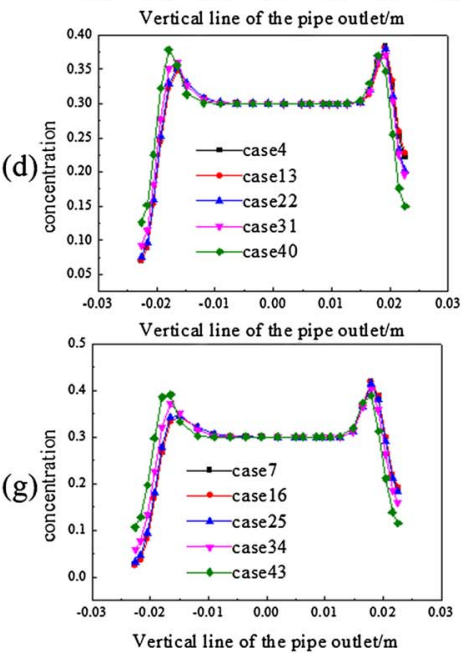

(b)

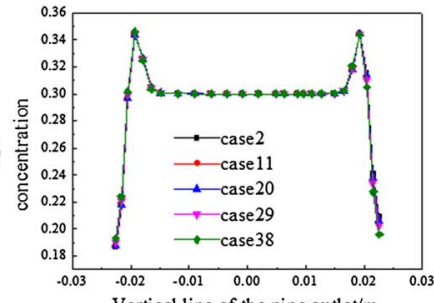

(e)

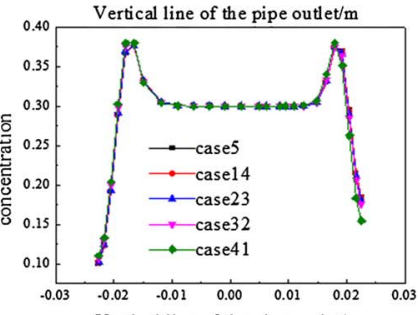

(h)

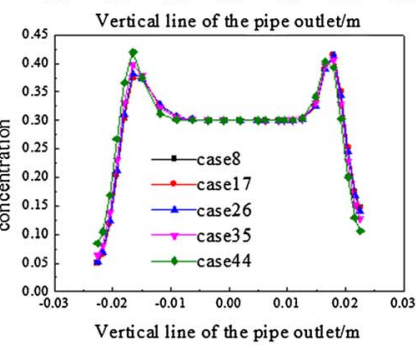

(c)

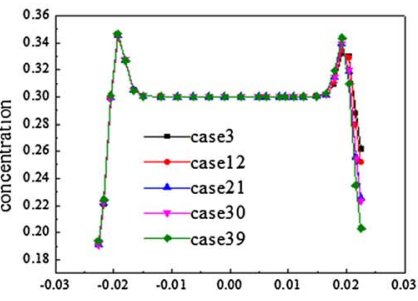

(f)

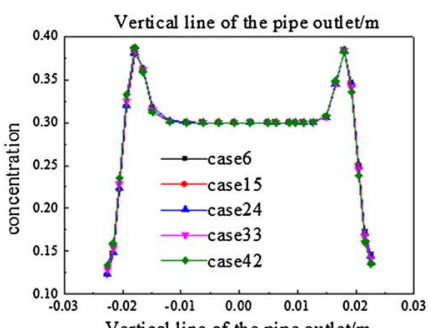

(i)

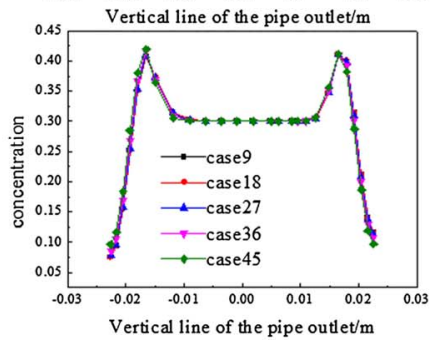

Fig. 10. XY plot of concentration distribution in the outlet radial cross section (cases 1-45).

becomes larger, the number of particles becomes less, and the collision friction between the particles and the particles, the particles and the fluid or the particles and the wall becomes less. Therefore, the flow pressure drop of the hydrate slurry decreases as the particle size of the hydrate particles increases. 


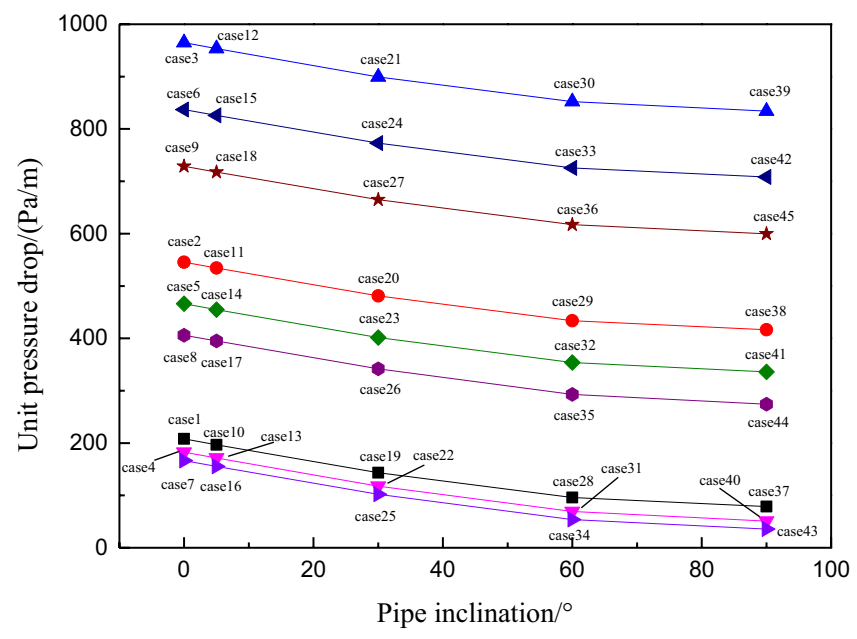

Fig. 11. Pressure gradient diagram in pipe under different working conditions (cases 1-45).

As mentioned above, when only the flow pressure drop is considered, the larger the inclination of the pipe, the smaller the flow pressure drop. Therefore, transporting the hydrate slurry with a large angle of inclination pipe is beneficial to reduce the flow pressure drop. At the same time, the lower flow rate and larger initial particle size are beneficial to the reduction of the flow pressure drop of the hydrate slurry. Therefore, controlling the flow rate and the initial particle size of the hydrate is an effective measure to reduce the flow pressure drop in production.

\section{Conclusion}

The transport of hydrate slurry in pipes with different inclination on the seabed is an important part of hydrate solid fluidized mining. In this paper, the FLUENT software is used to simulate the flow state of different inclination angles hydrate slurry pipes under different working conditions, which provides parameter guidance for hydrate slurry transport and solid fluidized mining. After analyzing the simulation results, the main conclusions are as follows:

1. In terms of particle size distribution. In the transport of hydrate slurry, the larger the inclination of the pipe, the more homogeneous the particle size distribution of the hydrate, and the less likely it is to aggregate to form large hydrate particles. Moreover, the higher flow rate and lower initial particle size are favorable for the homogeneous distribution of the particle size of the hydrate slurry as well. This is beneficial to the safety of hydrate slurry transport.

2. In terms of concentration distribution. Similar to the particle size distribution, the larger pipe inclination is favorable for the homogeneous distribution of hydrate concentration, which is beneficial for the safe transportation of hydrate. What's more, larger flow rates make the hydrate slurry concentration to be more homogeneous across the pipe section. Therefore, the probability of agglomerated implantation of hydrates due to gravity is reduced, and the risk of shrinking the cross-sectional area of the pipe and even blocking the pipe is reduced. As the particle size increases, the hydrate slurry concentration distribution will be more heterogeneous. And although the high concentration zone of the hydrate slurry will move closer to the center of the pipe, the maximum concentration will increase, which is increasing the risk of blocking. Therefore, from the aspect of concentration, large pipe inclination, large flow rate and small initial particle size are favorable for the safe transportation of the hydrate slurry.

3. In terms of flow pressure drop, the larger the inclination of the pipe, the smaller the pressure gradient. Therefore, the inclination of the pipe will not adversely affect the flow friction of the hydrate transport, but will reduce the flow pressure drop. Apart from this, the lower flow rate and larger initial particle size are beneficial to the reduction of the flow pressure drop of the hydrate slurry.

Acknowledgments. This work was supported by Shandong Provincial Natural Science Foundation, China (Grant No. ZR2017MEE057), the Fundamental Research Funds for the Central Universities (14CX02207A, 17CX05006, 17CX06017) and the Graduate Innovation Project of China University of Petroleum (East China) (YCX2017062), which are gratefully acknowledged.

\section{References}

1 Sloan E.D. Jr (2003) Fundamental principles and applications of natural gas hydrates, Nature 426, 6964, 353-363.

2 Sloan E.D., Koh C., Sum A.K. (2010) Natural gas hydrates in flow assurance, Gulf Professional Publishing, United States.

3 Hammerschmidt E.G. (1934) Formation of gas hydrates in natural gas transmission lines, Ind. Eng. Chem. 26, 851-855.

4 Lederhos J.P., Long J.P., Sum A., Christiansen R.L., Jr E.D. S. (1996) Effective kinetic inhibitors for natural gas hydrates, Chem. Eng. Sci 51, 8, 1221-1229.

5 Daraboina N., Malmos C., von Solms N. (2013) Synergistic kinetic inhibition of natural gas hydrate formation, Fuel 108, 11, 749-757.

6 Saikia T., Mahto V. (2018) Temperature augmented visual method for initial screening of hydrate inhibitors, Oil Gas Sci. Technol. - Rev. IFP Energies nouvelles 73, 1.

7 Vysniauskas A., Bishnoi P.R. (1983) A kinetic study of methane hydrate formation, Chem. Eng. Sci. 38, 7, 1061-1072.

8 Makogon Y.F., Holditch S.A., Makogon T.Y. (2007) Natural gas-hydrates - A potential energy source for the 21st Century, J. Pet. Sci. Eng. 56, 1, 14-31.

9 Chong Z.R., Yang S.H.B., Babu P. (2016) Review of natural gas hydrates as an energy resource: Prospects and challenges, Appl. Energy 162, 1633-1652.

10 Hao Y.M., Li X.Z., Li S.X., Lü G.Z., Liu Y.Y., Wei X.L. (2018) Heat conduction and thermal convection on thermal front movement during natural gas hydrate thermal stimulation exploitation, Oil Gas Sci. Technol. - Rev. IFP Energies nouvelles 73, 40. 
11 Song Y., Yang L., Zhao J. (2014) The status of natural gas hydrate research in China: A review, Renew. Sust. Energ. Rev. 31, 2, 778-791.

12 Max M.D., Johnson A.H. (2014) Hydrate petroleum system approach to natural gas hydrate exploration, Petrol. Geosci. 20, 2, 187-199.

13 Vedachalam N., Srinivasalu S., Rajendran G. (2015) Review of unconventional hydrocarbon resources in major energy consuming countries and efforts in realizing natural gas hydrates as a future source of energy, J. Nat. Gas Sci. Eng. 26, 163-175.

14 Boswell R., Collett T.S. (2011) Current perspectives on gas hydrate resources, Energ. Environ. Sci. 4, 4, 1206-1215.

15 Zhou S., Chen W., Qingping L.I. (2017) Research on the solid fluidization well testing and production for shallow nondiagenetic natural gas hydrate in deep water area, China Offshore Oil Gas, 1-8.

16 Zhou S., Zhao J., Li Q. (2018) Optimal design of the engineering parameters for the first global trial production of marine natural gas hydrates through solid fluidization, Nat. Gas Ind. B, 118-131.

17 Balakin B.V., Hoffmann A.C., Kosinski P. (2011) Experimental study and computational fluid dynamics modeling of deposition of hydrate particles in a pipeline with turbulent water flow, Chem. Eng. Sci. 66, 4, 755-765.

18 Balakin B.V., Hoffmann A.C., Kosinski P. (2010) Population balance model for nucleation, growth, aggregation, and breakage of hydrate particles in turbulent flow, AIChE J. 56, 8, 2052-2062.

19 Fatnes E.D. (2010) Numerical simulations of the flow and plugging behaviour of hydrate particles, The University of Bergen, Bergen, Norway, Hydrate.

20 Song G.C., Li Y.X., Wang W.C. (2018) Investigation on the mechanical properties and mechanical stabilities of pipewall hydrate deposition by modelling and numerical simulation, Chem. Eng. Sci. 192, 477-487.

21 Song G.C., Li Y.X., Wang W.C. (2018) Hydrate agglomeration modelling and pipeline hydrate slurry flow behavior simulation, Chin. J. Chem. Eng, 32-43.

22 Song G.C., Li Y.X., Wang W.C. (2018) Numerical simulation of hydrate slurry flow behavior in oil-water systems based on hydrate agglomeration modelling, J. Pet. Sci. Eng. 169, 393-404.

23 Song G.C., Li Y.X., Wang W.C. (2018) Numerical simulation of pipeline hydrate particle agglomeration based on population balance theory, J. Nat. Gas Sci. Eng. 51, 251-261.

24 Liu Y., Tang X., Hu K. (2018) Study on flow characteristics of natural gas hydrate slurry with decomposition in vertical tube, Chemistry, 267-273.

25 Balakin B.V., Pedersen H., Kilinc Z., Hoffmann A.C., Kosinski P., Hoiland S. (2010) Turbulent flow of Freon R11 hydrate slurry, J. Pet. Sci. Eng. 70, 3-4, 177-182.

26 Ding J., Gidaspow D. (1990) A bubbling fluidization model using kinetic theory of granular flow, AIChE J. 36, 4, 523538.

27 Pabst W. (2004) Fundamental considerations on suspension rheology, Proc. Royal Soc. Lond. A Math. Phys. Eng. Sci. 48, 1, 6-13.

28 Thomas D.G. (1965) Transport characteristics of suspension: VIII. A note on the viscosity of Newtonian suspensions of uniform spherical particles, J. Colloid Sci. 20, 3, 267-277.

29 Ramkrishna D. (2000) Population balances: Theory and applications to particulate systems in engineering, Academic Press, United Kingdom, London.

30 Camp T.R., Stein P.C. (1943) Velocity gradients and internal work in fluid motion, J. Boston Soc. Civ. Eng. 85, 219-237.

31 Abrahamson J. (1975) Collision rates of small particles in a vigorously turbulent fluid, Chem. Eng. Sci 30, 11, 1371-1379.

32 Saffman P.G., Turner J.S. (1956) On the collision of drops in turbulent clouds, J. Fluid Mech. 1, 1, 16-30.

33 Van de Ven T.G.M., Mason S.G. (1977) The microrheology of colloidal dispersions VII. Orthokinetic doublet formation of spheres, Colloid Polym. Sci. 255, 5, 468-479.

34 Filimonov R. (2014) CFD modeling of dispersion water feed in wastewater cleaning application, MSc Dissertation, Lappeenranta University of Technology, Finnish.

35 Song G.C., Li Y.X., Wang W.C. (2017) Investigation of hydrate plugging in natural gas + diesel oil + water systems using a high-pressure flow loop, Chem. Eng. Sci. 158, 480-489.

36 Lv X.F., Shi B.H., Wang Y., Tang Y.X., Wang L.Y., Gong J. (2015) Experimental study on hydrate induction time of gassaturated water-in-oil emulsion using a high-pressure flow loop, Oil Gas Sci. Technol. - Rev. IFP Energies nouvelles 70, 6, 1111-1124.

37 Balachandar S., Eaton J.K. (2010) Turbulent dispersed multiphase flow, Adv. Mech. 42,1, 111-133. 